\title{
Geometrical nonlinearities on the static analysis of highly flexible steel cable-stayed bridges
}

\author{
A.M.S. Freire ${ }^{\text {a }}$, J.H.O. Negrão ${ }^{\text {b,* }}$, A.V. Lopes ${ }^{\text {b }}$ \\ ${ }^{a}$ Department of Civil Engineering, Polytechnic Institute of Castelo Branco, 6000-767 Castelo Branco, Portugal \\ ${ }^{\mathrm{b}}$ Department of Civil Engineering, University of Coimbra, 3030-290 Coimbra, Portugal
}

Received 22 August 2005; accepted 8 August 2006

Available online 27 October 2006

\begin{abstract}
An evaluation of the importance of geometrically nonlinear effects on the structural static analysis of steel cable-stayed bridges is presented. A finite element model is analyzed using linear, pseudo-linear and nonlinear methods. The pseudo-linear approach is based on the modified elastic modulus. The nonlinear analysis involves cable sag, large displacement and beam-column effects. The results confirm that both cable sag and large displacement originate the most important nonlinear effects in those structures. Beam-column effects are irrelevant for service loads. Both the pseudo-linear approach and the modified modulus element prove to be very limited or even inappropriate.
\end{abstract}

(c) 2006 Elsevier Ltd. All rights reserved.

Keywords: Cable-stayed bridges; Nonlinear analysis; Large displacements; Beam-column; Cable sagging

\section{Introduction}

As the span of modern cable-stayed bridges increases, so does the concern about the safety and reliability of these structures, resulting in the need for more realistic analysis models, in which the consideration of the geometrical and material nonlinear effects cannot be disregarded. In order to match the design geometry, expressed by the socalled "dead load condition", and the constraints on the displacements and stresses, both a precise evaluation of loadings and of its nonlinear effects must be undertaken. This accuracy is critical in the evaluation of the stretching forces of the cables, which in turn condition the stiffness and strength of the whole structure.

Though some sources of materially nonlinear behaviour, such as layered bearings or special seismic devices, may have to be considered in the analysis, most nonlinear

\footnotetext{
* Corresponding author. Tel.: +351 239797 240; fax: +351 239797242. E-mail address: jhnegrao@dec.uc.pt (J.H.O. Negrão).
}

responses of steel cable-stayed bridges have their origin in geometric causes.

There are three main sources of geometrically nonlinear behaviour of cable-stayed bridges: the beam-column effect, the large displacements (known as $P-\Delta$ ) effect and the cable sag effect [1]. It is generally accepted that the latter is the most relevant of those and, as a consequence, its consideration is mandatory in cable-stayed bridge design, even for simplified models of such structures and relatively small spans.

The main goal of this paper is to highlight the relative importance of those geometrically nonlinear effects, by comparing the results provided by a number of finite element based analyses of a cable-stayed bridge. The geometric and mechanic characteristics of the structural model were based on those from Refs. [2,3], which in turn were established through the use of a nonlinear optimization package with constraints in stresses and deflections. Despite its modest dimensions, the bridge shows a highly flexible behaviour.

Algorithms for the evaluation of each geometrically nonlinear effect were implemented and combined and the 
corresponding results were checked against those provided by the linear approach. When relevant, alternative nonlinear procedures were tested for the same effect, as it was the case for the cable sagging.

\section{Geometrically nonlinear effects}

In the last decades, several finite elements have been proposed for cable modelling (see e.g. [4-11]), though not specifically for the analysis of cable-stayed bridges. Nevertheless, some such elements have been extensively used in these structures (e.g. the modified elastic modulus element). In this study, three approaches for modelling the cables were considered: the elastic catenary element, the multiple-straight link discretisation and the modified modulus method. Both the element formulations and the nonlinear solver were implemented by the authors. The results were compared and checked against those provided by other elements referred to in the literature.

Beam-column effect can be carried out either through the use of stability functions or by considering a narrow mesh refinement with a finite element solver accounting for large displacements. The first option was considered in this study.

\subsection{Cables and sag effect}

\subsubsection{Truss element. Bar with modified modulus of elasticity. Multiple-straight link}

The truss element is the simplest option for modelling the cables of cable-stayed bridges. It may be used both in static and dynamic analysis, on condition that the tensile stresses in the cables are high enough to make the sag effect neglectable. In order to allow large displacements to be handled, geometrical stiffness factors have to be added to the mathematical formulation of the element.

The multiple-straight link approach is one of the most powerful ways for modelling the actual behaviour of cables using truss elements, allowing for both the sag effect due to the self weight and the vibration modes of the cables to be accounted for. The present study concerns static loading only, allowing the cables, modelled as chain-links, to be solved separately as independent substructures subject to self weight and differential displacements of boundary nodes. The analysis of each of these subsystems is performed by a nonlinear algorithm, implemented by the authors, which efficiently solve those highly hypostatic structures, imposing limits both on positive normal stress and on anchorage angles as restrictions for accurate convergences. Anchorage reactions are thus computed, among other useful output, and applied to the main structure. This iterative procedure will continue until convergence is achieved in both the cables and the remaining structure.

The Ernst method or modified elastic modulus method is often used in the analysis of cable-stayed bridges, given its capability to account for the sag effect and the ease of use, combining a rather simple mathematical formulation with a linear analysis methodology. The fictitious modified elastic modulus results in a length change for the chord defined by the cable anchorages which is the same as the length change caused by both the catenary and the elastic extension effects in the actual curved cable. The method assumes a parabolic instead of a catenary shape for the cable, which is acceptable only for moderate curvatures, typical of highly tensioned cables. The modified modulus $E_{\text {eq }}$ can be expressed by either of the equalities

$$
\begin{aligned}
E_{\mathrm{eq}} & =E \frac{1}{1+\frac{q^{2} L_{\mathrm{h}}^{2}}{12 T^{3}} E A}=E \frac{1}{1+\frac{\gamma^{2} E}{12 \sigma^{3}} L_{\mathrm{h}}^{2}} \\
& =E \frac{1}{1+\frac{\gamma^{2} E}{12 \sigma^{3}}\left(L_{0} \cos \alpha\right)^{2}}
\end{aligned}
$$

where $T, L_{\mathrm{h}}, q, E, L_{0}$ and $A$ are the cable tension, the horizontal component of the cable chord, the self weight per length unit, the Young modulus of the material, the unstretched length and the cable cross section, respectively. $\sigma=T / A$ is the normal stress, $\gamma=q / A$ the specific weight and $\cos \alpha=L_{\mathrm{h}} / L_{0}$.

In order to highlight the main differences between standard truss elements and modified elastic modulus truss elements, let's set the bar axial rigidity $E A / L_{0} \equiv\left(E A / L_{0}\right)^{*}$ constant. Hence, a longer bar must have a larger cross section, in the linear proportion $A=L_{0}\left(E A / L_{0}\right)^{*} / E$, so each bar presents a different ultimate tension $T_{\mathrm{u}}=\sigma_{\mathrm{u}} A$. Then, Eq. (1) can be rewritten as

$$
E_{\text {eq }}=E \frac{1}{1+\frac{L_{0}^{5}}{12}\left[\left(\frac{E A}{L_{0}}\right)^{*} \frac{1}{T}\right]^{3}\left(\frac{\gamma \cos \alpha}{E}\right)^{2}}
$$

which, for several initial lengths $L_{0}$, results in a set of curves bounded by

$$
E_{\text {eq }}=E \frac{1}{1+\frac{E^{3}}{12 \sigma_{\mathrm{u}}^{5}}\left[\frac{\gamma \cos \alpha}{\left(E A / L_{0}\right)^{*}} T\right]^{2}}
$$

as can be seen in Fig. 1 , where $E A / L_{0}=2 \times 10^{5} \mathrm{kN} / \mathrm{m}$, $\gamma=77 \mathrm{kN} / \mathrm{m}^{3}, \sigma_{\mathrm{u}}=4 \times 10^{5} \mathrm{kPa}$ and $\alpha=0^{\circ}$. Therein, the bullets represent the rupture of each cable. It can be concluded that long cables will hardly achieve full material stiffness. Fig. 2 is similar to Fig. 1 but expressed in terms of normal stress $\sigma$.

Although the method is suited for a (pseudo-)linear approach, some authors have proposed its use for nonlinear analysis [5,12-14], where geometrical stiffness terms have to be added. As Eq. (1) is not suitable for use in that kind of analysis, the cable stress must be iteratively computed by using the auxiliary function

$F=\sigma-E \frac{1}{1+\frac{\gamma^{2} L_{h}^{2}}{12 \sigma^{3}} E} \varepsilon=0$

where $\varepsilon=\Delta L / L_{0}$ is the axial engineering strain.

As it can be seen in Fig. 3, where plots of $F$ are shown, not all the solutions of Eq. (4) are physically meaningful (positive). This situation may also be verified using the 


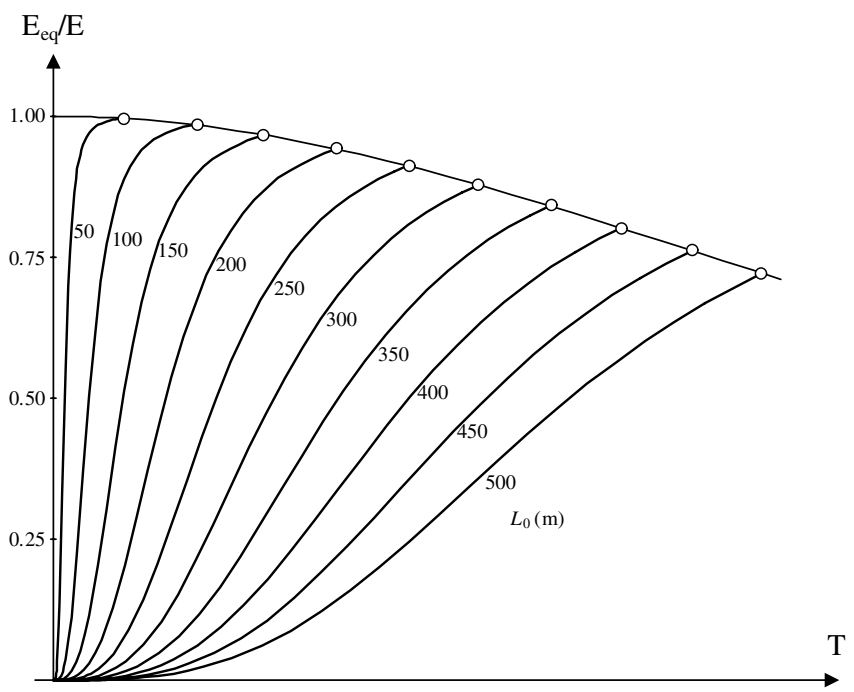

Fig. 1. Modified elastic modulus vs. tension. Axial stiffness EA $/ L_{0}$ is kept constant.

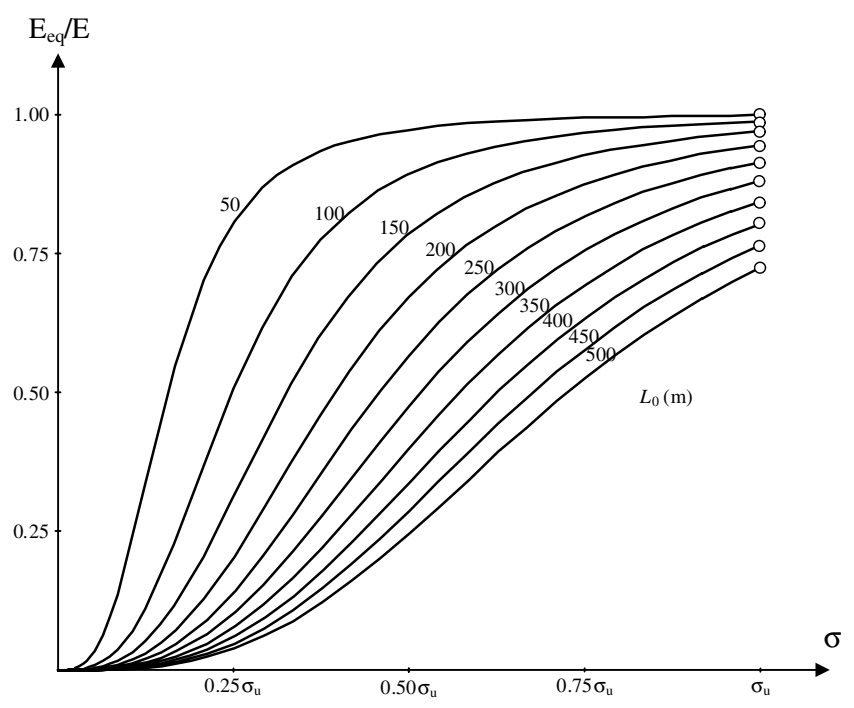

Fig. 2. Modified elastic modulus vs. normal stress. $\sigma_{\mathrm{u}}$ is the ultimate stress. Axial stiffness $\mathrm{EA} / L_{0}$ is kept constant.

secant form of Eq. (1). In fact, it is possible for a specific iteration, where $L_{\mathrm{h}}$ and $\Delta L$ are known, that $\sigma$ can be non-positive even when the cable is stretched (bolded line in Fig. 3), for lower $\varepsilon$ values. On the other hand, for higher $\varepsilon$ values, two positive solutions can actually be achieved; therefore, an effective Newton-Raphson procedure must be implemented. One can realise that the method is not completely reliable and for that reason it must be used carefully.

\subsubsection{The catenary element}

Consider an infinitesimal portion of an elastic cable subjected to its self weight. The vertical equilibrium condition, as presented in Fig. 4, can be expressed by

$F_{\mathrm{h}} \tan (\alpha+\mathrm{d} \alpha)-F_{\mathrm{h}} \tan \alpha=q \mathrm{~d} s_{0}$

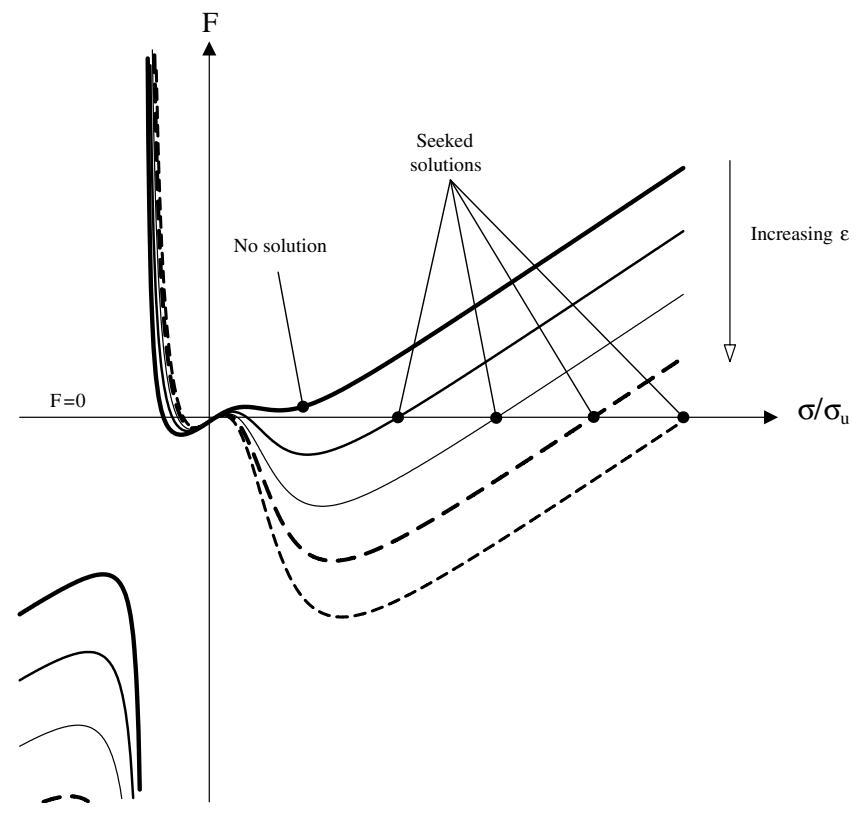

Fig. 3. $F$ function plotting. $\sigma_{\mathrm{u}}$ is the ultimate stress of cable material.

The compatibility equations can be deduced from Fig. 5 and be written as

$$
\begin{aligned}
& \mathrm{d} s_{\mathrm{v}}=\sin \alpha \mathrm{d} s_{0}+\frac{F_{\mathrm{h}}}{E A} \tan \alpha \mathrm{d} s_{0} \\
& \mathrm{~d} s_{\mathrm{h}}=\cos \alpha \mathrm{d} s_{0}+\frac{F_{\mathrm{h}}}{E A} \mathrm{~d} s_{0}
\end{aligned}
$$

Eq. (5) is rewritten using the relation

$$
\tan (\alpha+\mathrm{d} \alpha)-\tan \alpha \approx \mathrm{d} \alpha \sec ^{2} \alpha
$$

and the resulting equation introduced in Eqs. (6) and (7). Then, integrating it in $\alpha \in\left[\alpha_{A} ; \alpha_{B}\right]$ and $s_{0} \in\left[0 ; L_{0}\right]$, the equilibrium and compatibility equations become

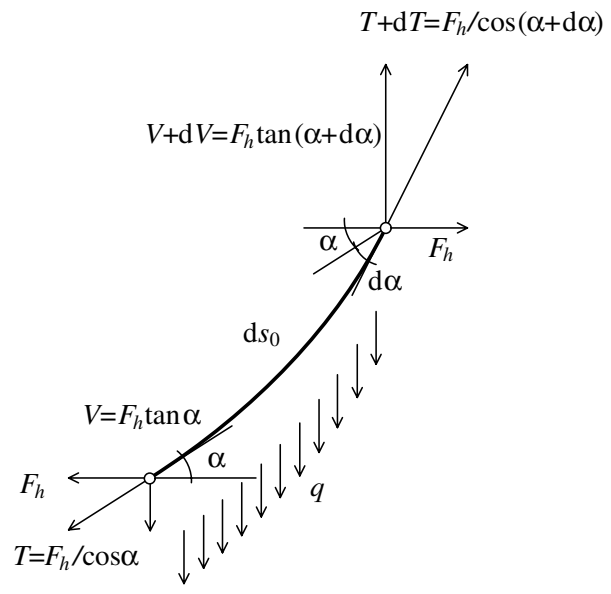

Fig. 4. Equilibrium of an infinitesimal portion of an elastic catenary. 


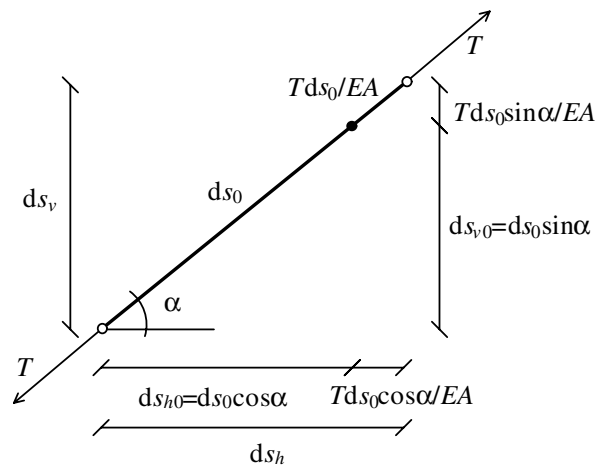

Fig. 5. Vertical and horizontal components of an infinitesimal portion of an elastic catenary.

$$
\begin{aligned}
& F_{\mathrm{h}}\left(\tan \alpha_{B}-\tan \alpha_{A}\right)-q L_{0}=0 \\
& L_{\mathrm{v}}-\frac{F_{\mathrm{h}}}{q}\left(\sec \alpha_{B}-\sec \alpha_{A}\right)-\frac{F_{\mathrm{h}}^{2}}{q E A} \frac{1}{2}\left(\sec ^{2} \alpha_{B}-\sec ^{2} \alpha_{A}\right)=0 \\
& L_{\mathrm{h}}-\frac{F_{\mathrm{h}}}{q} \ln \left[\frac{2}{\left.1+\sec \frac{\alpha_{A}+\alpha_{B}}{2} \sin \frac{\alpha_{A}-\alpha_{B}}{2}-1\right]}\right. \\
& \quad-\frac{F_{\mathrm{h}}^{2}}{E A q}\left(\tan \alpha_{B}-\tan \alpha_{A}\right)=0
\end{aligned}
$$

which can be formally written as $\mathbf{G}\left(F_{\mathrm{h}}, \alpha_{A}, \alpha_{B}\right)=\mathbf{0}$. The horizontal component of the anchorage force, $F_{\mathrm{h}}$ and the anchorage angles $\alpha_{A}$ and $\alpha_{B}$ for the exact elastic catenary element can be obtained from Eq. (9), in which $L_{\mathrm{v}}$ is the cable's vertical length between anchorage nodes, and $L_{0}$ is the unstretched cable length. The meanings of the remaining symbols are as previously defined. The values provided by system (9) fully agree with those obtained using either the equations from [4] or from [11].

The non-trivial plotting shown in Fig. 6 represents the solutions $F_{\mathrm{h}}$ of Eq. (9), obtained using a Newton-like method inserted into a path-following algorithm imple-

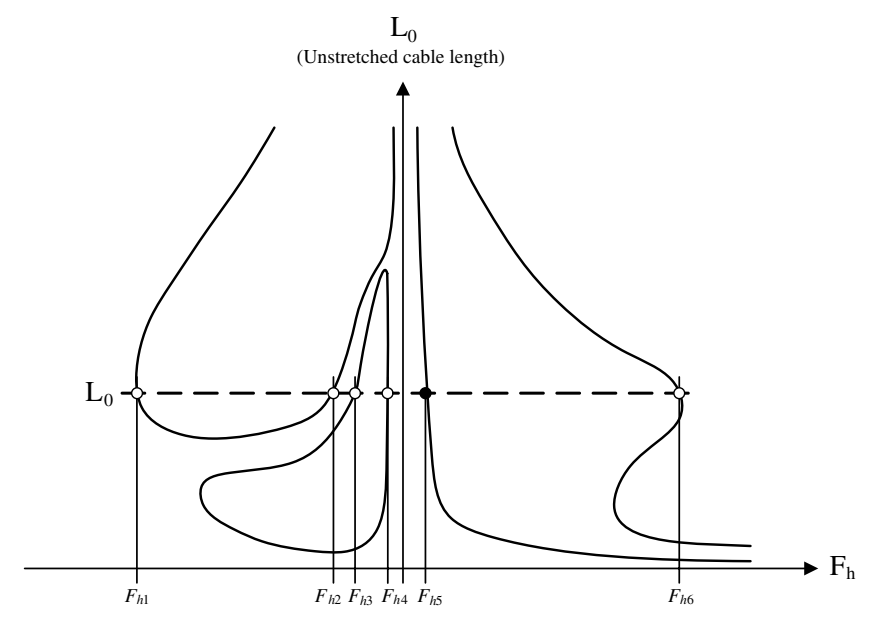

Fig. 6. Implicit plotting of $F_{\mathrm{h}}$ vs. $L_{0} . F_{\mathrm{h} i}$ are possible solutions for the horizontal component force of the elastic catenary, whereas $F_{\mathrm{h} 5}$ is the wanted one. mented by the authors from the methods proposed in $[15,16]$, which allows the search of solutions of parameterized nonlinear equations.

Let's set some values, regardless of their plausibility, say $q=2.5, \quad L_{\mathrm{h}}=50.0 ; \quad L_{\mathrm{v}}=45.0 \quad$ and $E A=2000$. For $L_{0}=1200$, the following roots can be found:

$$
\left\{\begin{array}{l}
F_{\mathrm{h} 1}=-1.659 \times 10^{3} \\
F_{\mathrm{h} 2}=-3.868 \times 10^{2} \\
F_{\mathrm{h} 3}=-2.121 \times 10^{2} \\
F_{\mathrm{h} 4}=-1.345 \times 10^{1} \\
F_{\mathrm{h} 5}=9.628 \text { correct } \\
F_{\mathrm{h} 6}=1.895 \times 10^{3}
\end{array}\right.
$$

Only one of these solutions is acceptable, despite the fulfilment of the equilibrium and compatibility conditions of all of them, allowing a stretched deformed cable configuration in stable equilibrium, which verify $F_{\mathrm{h}} \geqslant 0, \alpha_{A} \in[-\pi /$ $\left.2 ; \arctan \left(L_{\mathrm{v}} / L_{\mathrm{h}}\right)\right]$ and $\alpha_{B} \in\left[\arctan \left(L_{\mathrm{v}} / L_{\mathrm{h}}\right) ; \pi / 2\right]$. The formal procedure must be able to select the right one, based on both requirements of stable equilibrium and kinematics. Assuming that the solution for conventional cables/ropes is within a narrow-band in the positive side of both $L_{0}$ and $F_{\mathrm{h}}$ axes, one can force the iterative procedure to keep computing within that narrow-band until the residual error becomes less than an imposed tolerance. Ahmadi-Kashani and Bell [4] present a similar study of the solution curves, where only the solutions $F_{\mathrm{h} 3}, F_{\mathrm{h} 4}$ and $F_{\mathrm{h} 5}$ were presented and discussed. Despite its simplicity, the procedure presented therein to achieve $F_{\mathrm{h} 5}$ seems to work without problems.

To avoid the non-trivial procedure used to achieve the above results, one can use the well-known pure catenary formulation to find initial values for $F_{\mathrm{h}}, \alpha_{A}$ and $\alpha_{B}$ to be used in the predictor-corrector Newton-Raphson standard method to solve Eq. (9). As an example, let's assume that $q=1.0 \mathrm{kN} / \mathrm{m}, \quad L_{0}=100 \mathrm{~m}, \quad L_{\mathrm{h}}=40.0, \quad L_{\mathrm{v}}=60.0$ and $E A=3 \times 10^{7} \mathrm{kN}$. The catenary parameter $c$ (coordinate of the apex of inelastic catenaries) can be obtained from (see e.g. [17])

$$
L_{0}-\frac{2 c \sinh \frac{L_{\mathrm{h}}}{2 c}}{\sqrt{1-\frac{L_{\mathrm{v}}^{2}}{L_{0}^{2}}}}=0
$$

leading to $c=9.18561 \mathrm{~m}$. The horizontal force results $F_{\mathrm{h}}=q c=9.18561 \mathrm{kN}$ and the angles are [18]

$$
\begin{aligned}
\alpha_{A}= & -\operatorname{sign}\left(\frac{L_{\mathrm{h}}}{2}-c \arctan \frac{L_{\mathrm{v}}}{L_{0}}\right) \\
& \times \arccos \frac{F_{\mathrm{h}}}{\sqrt{F_{\mathrm{h}}^{2}+\left[q c \sinh \left(\frac{L_{\mathrm{h}}}{2 c}-\arctan \frac{L_{\mathrm{v}}}{L_{0}}\right)\right]^{2}}}=-64.455^{\circ} \\
\alpha_{B}= & \arccos \frac{F_{\mathrm{h}}}{\sqrt{F_{\mathrm{h}}^{2}+\left[q c \sinh \left(\frac{L_{\mathrm{h}}}{2 c}-\arctan \frac{L_{\mathrm{v}}}{L_{0}}\right)-q L_{0}\right]^{2}}}=83.513^{\circ}
\end{aligned}
$$


Entering those values in the nonlinear system (9)

$$
\begin{aligned}
& \mathbf{G}\left(F_{\mathrm{h}}, \alpha_{A}, \alpha_{B}\right)=\mathbf{0} \rightarrow\left[\begin{array}{c}
F_{\mathrm{h}} \\
\alpha_{A} \\
\alpha_{B}
\end{array}\right]^{i+1} \\
& =\left[\begin{array}{c}
F_{\mathrm{h}} \\
\alpha_{A} \\
\alpha_{B}
\end{array}\right]^{i}-\mathbf{J}^{-1} \mathbf{G}^{i} \Rightarrow\left\{\begin{array}{l}
F_{\mathrm{h}}=9.18559 \mathrm{kN} \\
\alpha_{A}=-64.455^{\circ} \\
\alpha_{B}=83.5128^{\circ}
\end{array}\right.
\end{aligned}
$$

where $\mathbf{J}$ is the Jacobian. The stretching of the elastic cable is found to be only $\Delta L=0.000124 \mathrm{~m}$, since the tensile forces are very low and the axial stiffness is high. The final configuration of the cable is presented in Fig. 7. Singular points can be found, as well. Some of those are

$$
\begin{aligned}
& \left\{F_{\mathrm{h}}=-1.667 \times 10^{3} ; L_{0}=1.277 \times 10^{3}\right\} \\
& \left\{F_{\mathrm{h}}=-1.124 \times 10^{3} ; L_{0}=3.779 \times 10^{2}\right\} \\
\frac{\mathrm{d} \mathbf{G}}{\mathrm{d} L_{0}}=\mathbf{0} \Rightarrow & \left\{F_{\mathrm{h}}=-1.341 \times 10^{1} ; L_{0}=1.336 \times 10^{3}\right\} \\
& \left\{F_{\mathrm{h}}=1.793 \times 10^{3} ; L_{0}=4.376 \times 10^{2}\right\} \\
& \left\{F_{\mathrm{h}}=1.926 \times 10^{3} ; L_{0}=9.563 \times 10^{2}\right\}
\end{aligned}
$$

and

$$
\begin{aligned}
&\left\{F_{\mathrm{h}}=-1.220 \times 10^{3} ; L_{0}=1.008 \times 10^{3}\right\} \\
& \frac{\mathrm{d} \mathbf{G}}{\mathrm{d} F_{\mathrm{h}}}=\mathbf{0} \Rightarrow\left\{F_{\mathrm{h}}=-1.060 \times 10^{2} ; L_{0}=7.582 \times 10^{1}\right\} \\
&\left\{F_{\mathrm{h}}=-2.132 \times 10^{1} ; L_{0}=1.550 \times 10^{3}\right\}
\end{aligned}
$$

The tangent stiffness matrix is obtained by computing the full implicit derivatives of the vector defining the nodal forces, which are obtained from Eq. (9) and are implicit functions of $F_{\mathrm{h}}, \alpha_{A}$ and $\alpha_{B}$, with respect to each spatial displacement coordinates that are used to define $L_{\mathrm{v}}$ and $L_{\mathrm{h}}$ [18]. Due to the dimension of the equations, such vectors and matrices will not be presented here. If the stretching initial force at an end of the cable is known, Eq. (9) may be used to evaluate the real unstretched cable length $L_{0}$,

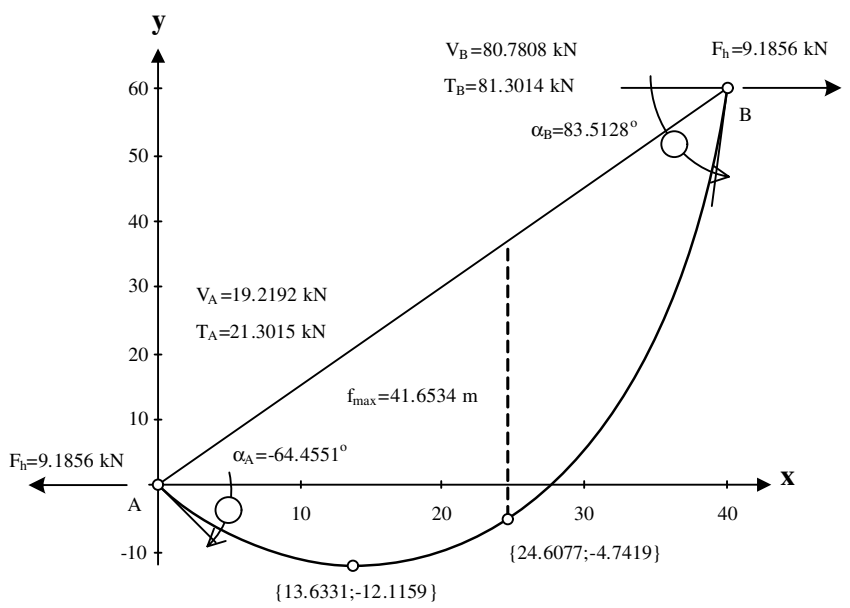

Fig. 7. Stable equilibrium cable configuration for $q=1.0 \mathrm{kN}, L_{0}=100 \mathrm{~m}$, $L_{\mathrm{h}}=40.0 ; L_{\mathrm{v}}=60.0$ and $\mathrm{EA}=3 \times 10^{7} \mathrm{kN}$. by defining a new Jacobian, obtained by differentiation in $L_{0}, \alpha_{A}$ and $\alpha_{B}[18]$.

\subsubsection{Parametric study concerning the different formulations}

Let $\delta$ be the horizontal displacement of the right anchorage node of a horizontal cable. Let also the initial horizontal projection of the cable be such that the initial horizontal component of the anchorage force $\left(F_{\mathrm{h}}\right)$ be null. For the elastic catenary element, this requires the two extreme nodes to be coincident, as can be seen in Fig. 8. For a horizontal modified elastic modulus element, where $T$ and $L_{\mathrm{h}}$ can be considered equal to, respectively, $F_{\mathrm{h}}$ and $L_{0}$, Eq. (1) writes

$E_{\text {eq }}=\lim _{T \rightarrow 0} \frac{E}{1+\frac{q^{2} L_{h}^{2}}{12 T^{3}} E A}=0$

and the displacement

$$
\delta_{2}=\lim _{T \rightarrow 0}\left[T \frac{L_{0}}{E_{\mathrm{eq}} A}\right]=\lim _{T \rightarrow 0}\left[T \frac{L_{0}}{E A}\left(1+\frac{q^{2} L_{\mathrm{h}}^{2}}{12 T^{3}} E A\right)\right]=\infty
$$

It can be seen in Fig. 8 that neither the truss element nor the modified elastic modulus element are in agreement with the elastic catenary element behaviour. The horizontal displacement with the increasing of $F_{\mathrm{h}}$ from zero for bar, modified modulus, elastic catenary and multiple-straight link modelling of cables is plotted in Fig. 9. Therein, one can identify $\delta_{1}, \delta_{3}$ and $\delta_{4}$ for $F_{\mathrm{h}}>0$ and $\delta_{2}$ (displacement related with the modified elastic modulus) for $F_{\mathrm{h}}=0$. As expected, multiple-straight link models lead to results

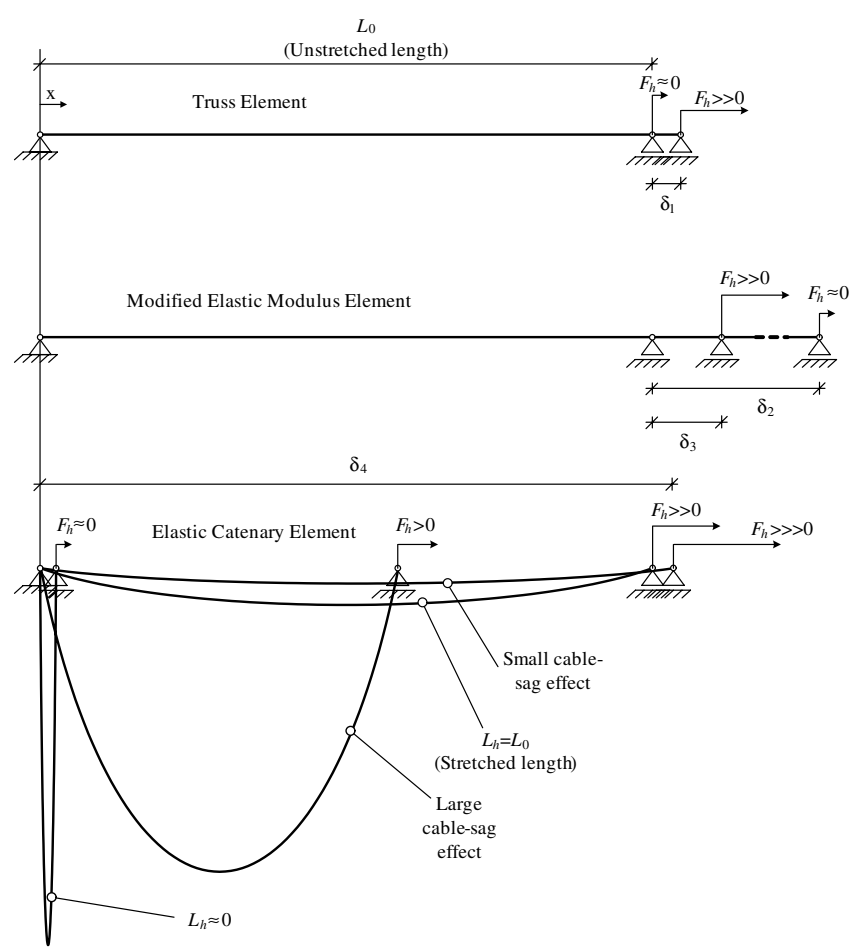

Fig. 8. Different modelling elements for cables: deformed configurations. 


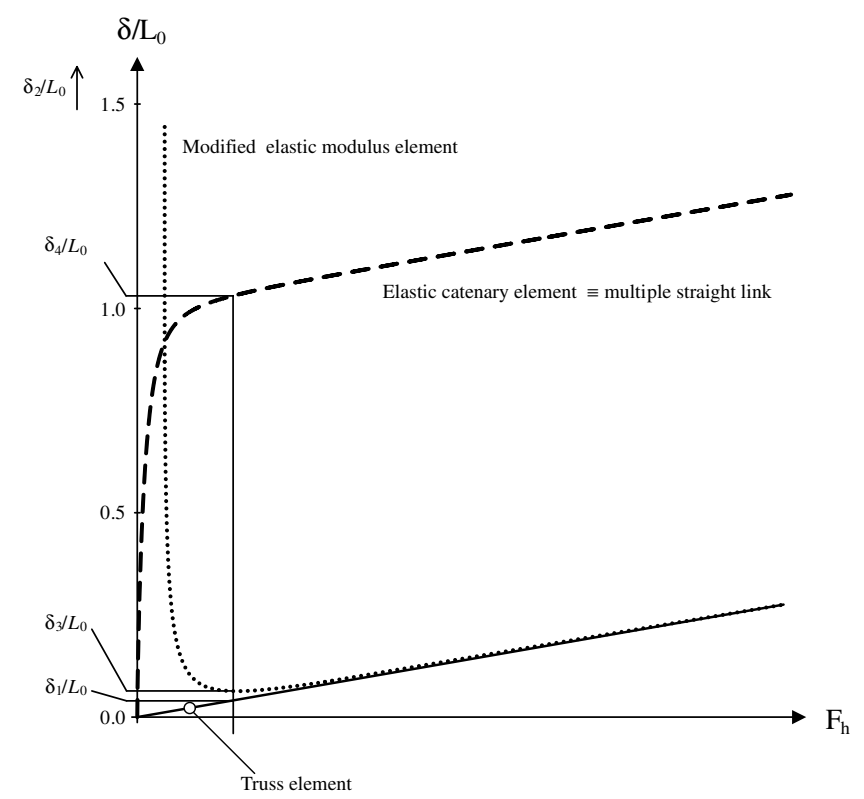

Fig. 9. Different modelling elements for cables: plotting of horizontal force $F_{\mathrm{h}}$ vs. horizontal displacement.

highly coherent with those from exact elastic catenary element. The question is in deciding on how many elements one should consider in order to have a reasonable accuracy. For the present parametric study, 20 nonlinear truss elements were considered. In a more detailed study [18], it was concluded that four chain-linked truss elements were enough in modelling cables of cable-stayed bridges. Nevertheless, the use of no less than six of such elements is recommended when neither catenary nor parabolic elements are available in the finite element package, particularly for the analysis of erection stages [18].

On the other hand, when tension is high, Eq. (1) results

$E_{\mathrm{eq}}=\lim _{T \rightarrow \infty} \frac{E}{1+\frac{q^{2} L_{\mathrm{h}}^{2}}{12 T^{3}} E A}=E$

and the displacement

$\delta=\lim _{T \rightarrow \infty}\left[T \frac{L_{0}}{E_{\text {eq }} A}\right]=\infty$

One can find the $T$ value

$\frac{\mathrm{d}}{\mathrm{d} T}\left[\frac{T L_{0}}{E A}\left(1+\frac{q^{2} L_{\mathrm{h}}^{2}}{12 T^{3}} E A\right)\right]=0 \rightarrow T=\sqrt[3]{\frac{E A\left(L_{\mathrm{h}} q\right)^{2}}{6}}$

leading to the lowest displacement

$\delta_{\min }=\frac{L_{0}\left(L_{\mathrm{h}} q\right)^{2}}{2} \sqrt[3]{\frac{9}{2\left[E A\left(L_{\mathrm{h}} q\right)^{2}\right]^{2}}}$

The related modified elastic modulus is

$E_{\text {eq }}=\frac{2}{3} E$
The tension value obtained from Eq. (20) can be understood as a lower limit for the use of Eq. (1).

As stated in [9], the modified elastic modulus element shows a less rigid path than the elastic catenary. However, this method seems to provide better results than truss elements in the modelling of cables. Nevertheless, it is almost a paradox that the modified elastic modulus method has been used to account for cable sag effect but it cannot be used when sag effect is of extreme relevance, as is the case with the erection stages.

An apparent elastic modulus can be obtained from the stiffness factor $K_{33}$ of the elastic catenary cable, which is the nodal horizontal force at the right-end side due to a differential horizontal displacement, as

$E_{\text {app }}=K_{33} \frac{L_{0}}{A}$

Assuming a horizontal cable configuration, one may compare the values with those from the modified elastic modulus element, obtained by increasing the horizontal force $F_{\mathrm{h}}$. The plot of Eq. (23) with the increasing $F_{\mathrm{h}}$ is almost the same as that obtained from the modified elastic modulus presented in Fig. 1, with the slight difference due to the tension $T$, which is, for a horizontal cable, $F_{\mathrm{h}}$ for the modified elastic element and $F_{\mathrm{h}} / \cos \alpha_{2}$ for the elastic catenary. In fact, the apparent axial stiffness of cables seems to be successfully simulated with the Ernst method. However, the configurations for each element in equilibrium with $F_{\mathrm{h}}$ are completely different, as it can be seen in Fig. 8. Once again, one concludes that the Ernst method is not suitable for neither nonlinear analysis, nor linear analysis of structures undergoing large displacements, nor linear analysis involving low tensioned cables.

\subsection{Deck and towers: the beam-column element}

A three-dimensional beam-column element was studied and developed to take into account full force interactions. Therefore, interactions of bending moments, torsion, axial forces and span loads, as well as complete bowing shortening effects, modify all stiffness coefficients, internal forces and equivalent external loads iteratively. Well known stability functions are used to modify the linear stiffness coefficients, while some others are established to carry out the remaining interactions. The main procedure is based in the adoption of a global system, defining the rigid body motion in space, and a basic system rigidly attached to the current configuration of the element, in which local displacement components induce the deformations in the beam. The whole procedure is implemented through a co-rotational formulation of three-dimensional beams (see e.g. [19-25]). The local displacements and rotations are "interpolated" using the stability functions presented below, specially defined to carry out the interactions referred above, which will be studied in this paper. A co-rotational technique, involving stability functions can be found in [20]. The differences in the co-rotational procedures found in the 
literature are essentially related to the parameterization of rotations of rigid bodies undergoing large motions. The procedure adopted is based in the one presented in [25] and will not be detailed here. Hence, large displacement effects on the structure can be said to be due to the rigid body motions, whereas the beam-column effects are taken to be due to the local deformations of the beam in its current configuration. As previously stated, beam-column effects can be included by mesh refinement using, for example, standard Bernoulli beam elements accounting for large displacements. Therefore, the stability functions have a relative impact in the structural response. Nevertheless, its effect will be evaluated for the sake of completeness.

Let's thus assume a horizontal beam with hinged connections in both ends, subjected to transversal constant loads $q_{i}$ and end moments $M_{A, i+1}$ and $M_{B, i+1}$ on the direction of the principal inertial axes $i=y$ and $i+1=z$ or $i=z$ and $i+1=y$, where the coordinates $x, y$ and $z$ define the local reference (body attached frame). $x$ is the element axis passing through the centroids of the cross sections of the undeformed beam. The differential equations are

$E I_{i+1} \frac{\mathrm{d}^{4} v_{i}}{\mathrm{~d} x^{4}}-P \frac{\mathrm{d}^{2} v_{i}}{\mathrm{~d} x^{2}}=q_{i}$

where $v_{i}(x)$ is the function describing the deformed elastic line in the $i=y$ (or $i=z$ ) direction, $P$ is the axial force, $E$ represents the Young modulus and $I_{i+1} \equiv I_{z}\left(\right.$ or $I_{i+1} \equiv I_{y}$ ) are the second moments of area. Using the boundary conditions

$\left.v_{i}\right|_{x=0}=0,\left.v_{i}^{\prime \prime}\right|_{x=0}=\frac{M_{A, i+1}}{E I_{i+1}},\left.v_{i}\right|_{x=L}=0$ and $\left.v_{i}^{\prime \prime}\right|_{x=L}=-\frac{M_{B, i+1}}{E I_{i+1}}$

the solution becomes

$$
\begin{aligned}
v_{i}(x)= & \frac{1}{E I_{i+1} k_{i+1}^{2}}\left[\left(\cosh k_{i+1} x+\frac{x}{L}-\frac{\cosh k_{i+1} L}{\sinh k_{i+1} L} \sinh k_{i+1} x-1\right) M_{A, i+1}\right. \\
& \left.+\left(\frac{x}{L}-\frac{1}{\sinh k_{i+1} L} \sinh k_{i+1} x\right) M_{B, i+1}\right] \\
& +\frac{q_{i}}{E I_{i+1}}\left[\frac{\cosh k_{i+1} x}{k_{i+1}^{4}}+\frac{L x}{2 k_{i+1}^{2}}-\frac{\operatorname{coth} k_{i+1} L}{k_{i+1}^{4}} \sinh k_{i+1} x\right. \\
& \left.-\frac{1}{k_{i+1}^{4}}-\frac{x^{2}}{2 k_{i+1}^{2}}+\frac{1}{k_{i+1}^{4} \sinh k_{i+1} L} \sinh k_{i+1} x\right]
\end{aligned}
$$

where

$k_{i+1}^{2}=\frac{P}{E I_{i+1}}$

Notice that $k^{2}$ is negative for a compression $P$ force. The curvature shortening, known as the bowing effect, can be expressed by

$$
\begin{aligned}
u_{b} & \approx u_{b, i}+u_{b, i+1} \\
& =\int_{0}^{L} \frac{1}{2}\left(\frac{\mathrm{d} v_{i}}{\mathrm{~d} x}\right)^{2} \mathrm{~d} x+\int_{0}^{L} \frac{1}{2}\left(\frac{\mathrm{d} v_{i+1}}{\mathrm{~d} x}\right)^{2} \mathrm{~d} x
\end{aligned}
$$

Inserting Eq. (26) into Eq. (28) one obtains

$$
\begin{aligned}
u_{b, i}= & \frac{\operatorname{cosech}^{2} k_{i+1} L}{8\left(E I_{i+1} k_{i+1}^{2}\right)^{2} L}\left[( M _ { A , i + 1 } ^ { 2 } + M _ { B , i + 1 } ^ { 2 } ) \left(2+2\left(k_{i+1} L\right)^{2}\right.\right. \\
& \left.-2 \cosh 2 k_{i+1} L+k_{i+1} L \sinh 2 k_{i+1} L\right) \\
& +2 M_{A, i+1} M_{B, i+1}\left(2 k_{i+1} L \sinh k_{i+1} L+2\left(k_{i+1} L\right)^{2}\right. \\
& \left.\left.\times \cosh k_{i+1} L-4 \sinh ^{2} k_{i+1} L\right)\right] \\
& +\frac{q_{i}^{2}}{24\left(E I_{i+1}\right)^{2} k_{i+1}^{7}}\left[k_{i+1} L\left(k_{i+1}^{2} L^{2}-6 \operatorname{sech}^{2} \frac{k_{i+1} L}{2}-24\right)\right. \\
& \left.+60 \tanh \frac{k_{i+1} L}{2}\right]+\frac{q_{i}\left(M_{A, i+1}-M_{B, i+1}\right)}{4\left(E I_{i+1}\right)^{2} k_{i+1}^{5}} \operatorname{sech}^{2} \frac{k_{i+1} L}{2} \\
& \times\left[3 \sinh k_{i+1} L-k_{i+1} L\left(\cosh k_{i+1} L+2\right)\right]
\end{aligned}
$$

The implicit axial force can then be written as

$P=\frac{E A}{L}\left[u+\left.u_{b, i}\right|_{q_{i}=0}+\left.u_{b, i+1}\right|_{q_{i+1}=0}\right]$

where $u$ is the axial stretching (or shortening) obtained in each iteration process.

The corresponding axial load $F$ due to transversal uniformed loads is obtained by considering $M_{A, i+1}=0$ and $M_{B, i+1}=0$ in Eq. (29) so

$F=\frac{E A}{L}\left[\left.u_{b, i}\right|_{M_{A, i+1}=0, M_{B, i+1}=0}+\left.u_{b, i+1}\right|_{M_{A, i}=0, M_{B, i}=0}\right]$

The stability functions for bending moments can be derived using a similar procedure, i.e. by considering $q_{i}=0$ in Eq. (26) and computing the first derivatives with respect to $x$ of the resulting equations to obtain the rotation functions of the deformed longitudinal axis. Knowing that

$\left.v_{i}^{\prime}\right|_{x=0}=\theta_{A, i+1},\left.\quad v_{i}^{\prime}\right|_{x=L}=\theta_{B, i+1}$

and solving the resulting equations with respect to the bending moments, one can conclude that

$M_{A, i+1}=\frac{E I_{i+1}}{L}\left(s_{i i, i+1} \theta_{A, i+1}+s_{i j, i+1} \theta_{B, i+1}\right)$
$M_{B, i+1}=\frac{E I_{i+1}}{L}\left(s_{i j, i+1} \theta_{A, i+1}+s_{i i, i+1} \theta_{B, i+1}\right)$

where the stability functions are given by

$$
\begin{aligned}
s_{i i, i+1} & =\frac{\left(k_{i+1} L\right)^{2} \cosh k_{i+1} L-k_{i+1} L \sinh k_{i+1} L}{2-2 \cosh k_{i+1} L+k_{i+1} L \sinh k_{i+1} L} \\
s_{i j, i+1} & =\frac{k_{i+1} L \sinh k_{i+1} L-\left(k_{i+1} L\right)^{2}}{2-2 \cosh k_{i+1} L+k_{i+1} L \sinh k_{i+1} L}
\end{aligned}
$$

The corresponding bending moments that are equivalent to in-span transversal uniform loads are derived from

$$
\begin{aligned}
v_{i}(x)= & \frac{q_{i}}{2 E I_{i+1} k_{i+1}^{3}}\left[k_{i+1} x(L-x)\right. \\
& \left.+2 L \operatorname{coth} \frac{k_{i+1} L}{2} \sinh ^{2} \frac{k_{i+1} x}{2}-L \sinh k_{i+1} x\right]
\end{aligned}
$$

which is obtained by imposing null displacements and null rotations at both ends, as boundary conditions to solve Eq. (24). Thus, from the second derivative of Eq. (35) with respect to $x$, one gets 


$$
\begin{aligned}
M_{F A, i+1} & =-M_{F B, i+1}=-\left.E I_{i+1} v_{i}^{\prime \prime}\right|_{x=0}=\left.E I_{i+1} v_{i}^{\prime \prime}\right|_{x=L} \\
& =\frac{q_{i} L^{2}}{12} \frac{3\left(\frac{k_{i+1} L}{2}-\tanh \frac{k_{i+1} L}{2}\right)}{\left(\frac{k_{i+1} L}{2}\right)^{2} \tanh \frac{k_{i+1} L}{2}}
\end{aligned}
$$

The torsional moments are given by (see e.g. [26])

$M_{t}=\frac{\phi}{L} \frac{\mathrm{GJ}-P \bar{r}}{1-\frac{2}{k L} \tanh \frac{\bar{k} L}{2}}$

where $\phi=\phi_{B}-\phi_{A}$ is the torsion angle, GJ the torsional stiffness, $\bar{r}$ the polar radius of gyration and

$\bar{k}=\sqrt{\frac{\left|\mathrm{GJ}-P \bar{r}^{2}\right|}{E c_{\omega}}}$

Therein $c_{\omega}$ is the warping constant. The shear forces are obtained from equilibrium considerations. To avoid numerical problems caused by using the standard form for the stability functions presented above, power series expansion in $k L$ and $\bar{k} L[18,19]$ were used instead. Such equations will not be presented.

\section{Structural analysis}

For the sake of comparison of results, both linear, pseudo-linear and nonlinear analysis were considered in this study, the particular issues of each approach being discussed in the following sections.

\subsection{Linear and pseudo-linear analysis}

The linear analysis of the numerical model of a steel cable-stayed bridge uses the standard beam and truss bar elements. Cable-stretching forces are applied as kinematic loads, by evaluating the shortening length of each truss element. The results obtained will be used as a reference for the comparative study.

Pseudo-linear analysis is a linear iterative method in which only the modified elastic modulus of the truss elements, used to model the stay-cables, is updated according to the current cable tension, to account for the cable sag effect. No geometry updating is made and so, as in linear analysis, out-of-balance forces are not evaluated, therefore no quality criterion can be used to check the accuracy of the solution. Its relevant advantage is that it may be undertaken with common linear analysis software.

\subsection{Nonlinear analysis}

Literature provides a large number of algorithms used to solve nonlinear mathematical problems. Among these, the Newton-Raphson method is probably the most well known. In the case of structural analysis, the load is usually subdivided into a series of load increments applied over several load steps. Then, the iterative Newton-Raphson method evaluates the out-of-balance force vector and checks for convergence. If convergence criteria are not met, the stiffness matrix and the out-of-balance force vector are updated.

When material is set to be elastic and isotropic and the solution path does not present any limit points, as snapthrough, snap-back or bifurcation, the loading may be applied in a single step and no increment procedure needs to be implemented. Besides, a modified Newton-Raphson method may be used in which the stiffness matrix must not be updated in each iteration. This usually results in computer time-consuming reduction, inasmuch as the update and factorization of the Jacobian is a heavy numerical task. Another important issue of this approach is that several load cases may be simultaneously analyzed by iteration procedure using the initial stiffness. Stresses, fixedend forces and in-span loads can be iteratively evaluated as differential displacements update the structural geometry. The solution is reached when differential displacements or unbalanced forces are smaller than some imposed tolerance.

The finite elements used in the present study were implemented to allow the use of the total Lagrangean method. The stretching forces are implicitly applied evaluating a new unstretched length from Eq. (9) for each cable, as stated in Section 2.1.2.

\section{Numerical examples}

In order to evaluate the efficiency of previously discussed methodologies, a double-plane cable-stayed steel bridge, shown in Fig. 10, is analyzed. No eccentric loads are applied and therefore no global torsion effects are important to the study presented in this paper. Girders with $[72.00+156.00+72.00] \mathrm{m}$ are supported by 24 pairs of cables. The towers are $69.32 \mathrm{~m}$ high and the deck, with a width of $20 \mathrm{~m}$, is $30 \mathrm{~m}$ above the foundation level. Relative horizontal displacements between deck and pylons are free in the longitudinal direction. The pylons have rectangular hollow sections and the stiffening girders are monosymmetric I-shaped. Design data such as web and flange width and thicknesses, beam depths and stretching forces of the stays are as defined in Refs. [2,3] and were set through the use of a finite element structural nonlinear optimization package. The detailed values of such data are available in the aforementioned references and shall not thus be included here.

\subsection{Description of the different analysis used}

For the present study, all types of analysis previously discussed were considered and so were all the sources of geometrical nonlinearity. Analysis methods are summarized in Table 1 and can be divided into three main groups: linear, which uses standard finite elements; pseudo-linear, which uses the modified elastic modulus element in an iterative procedure; nonlinear, which is subdivided with the nonlinear finite elements used. The nonlinear procedure called Multiple-straight link uses six truss elements to 


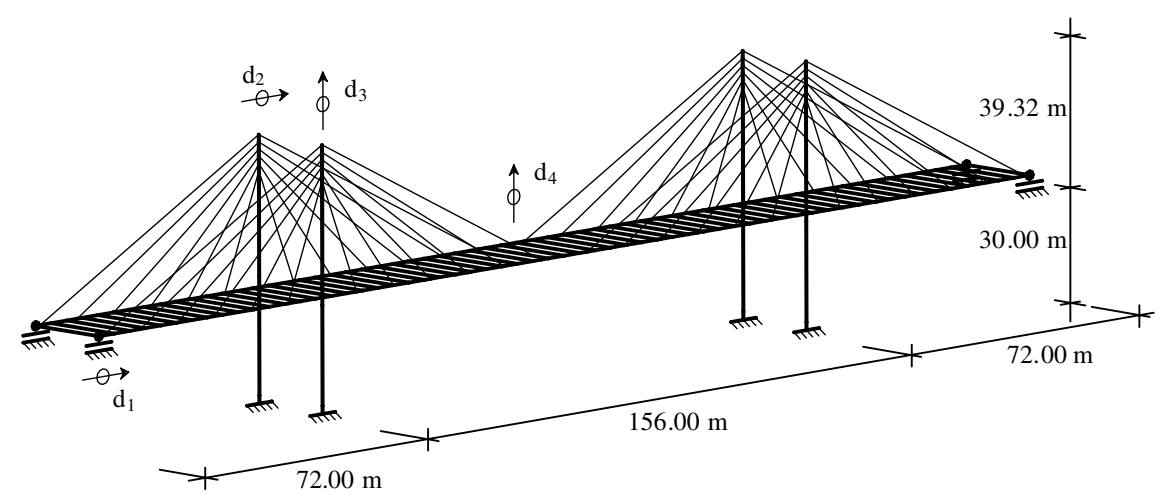

Fig. 10. Cable-stayed bridge.

Table 1

Sort of analysis and geometrical nonlinear effects considered

\begin{tabular}{|c|c|c|c|c|c|c|}
\hline \multicolumn{2}{|c|}{ Label and graphic bar reference } & \multirow[t]{2}{*}{ Sort of analysis } & \multicolumn{2}{|l|}{ Nonlinearity } & \multirow[t]{2}{*}{ Cable modelling } & \multirow[t]{2}{*}{ Expected accuracy } \\
\hline & & & Beam-column & $P-\Delta$ & & \\
\hline Linear & $\mathbf{\square}$ & Linear & - & - & Truss element & Poor \\
\hline Pseudo-linear & 目 & Pseudo-linear & - & - & Ernst modulus & Limited \\
\hline Multi-BC & 叉 & Nonlinear & Total & Total & Multiple-straight link & High \\
\hline Caten- $B C$ & $\square$ & Nonlinear & Total & Total & Elastic catenary & Exact \\
\hline Caten- $C$ & 毘 & Nonlinear & Partial & Total & Elastic catenary & High \\
\hline
\end{tabular}

model each cable, regardless of its length or internal tension. Beam-column effects, such as moment-axial force interactions and bowing effects, can be either taken into account or not: total uses full interactions of axial forces, bending moments, torsion, in-span loads and bowing, and its label is $B C$ (beam-column); partial does not consider shortening effects due to bowing in the stability functions and its label is $C$ (Column); the Caten-B $($ Catenary + Beam) analysis does not support interaction force (beam-column) effects. As previously mentioned, the linear analysis will be used as a comparative base.

The case of nonlinear analysis with the cables modelled as truss bars with modified elastic modulus was not included in this work. As reported in Section 2.1.1, roots obtained from Eq. (4) during the iterative process, for several stretched cables, were not physically meaningful. Actually, it was that situation that brought forward the study of Eq. (4), which highlighted the problems involving the tension finding for lower axial strain values.

\subsection{Load cases description}

Three main load cases were considered for the final structure, respectively, the action of live load all over the deck, outer spans or inner span only. Additionally, dead load only was considered for the geometry control of both the erection stages and the final structure. The dead and live loads are accounted for as uniform loads in the stiffening girders, its values being of, respectively, $30 \mathrm{kN} / \mathrm{m}$ and
$20 \mathrm{kN} / \mathrm{m}$. Self weight $\left(\gamma=77 \mathrm{kN} / \mathrm{m}^{3}\right)$ of all structural members was also considered.

\subsection{Results and discussion}

The cable-stayed bridge deformed configurations and bending moments due to each load case shown in Fig. 11 were obtained through a nonlinear analysis accounting for elastic catenary sag effects, large displacement effects and full beam-column effects, labelled in Table 1 as Caten-BC. To evaluate the differences obtained by using each numerical modelling of the structure, the displacement coordinates shown in Fig. 10 were considered and norms of the cable tensions due to each load case were calculated. The bending moments were evaluated in sampling sections of the deck and the towers. The linear analysis labelled as Linear is used as the reference, thus corresponding to $100 \%$ values in graphs of Figs. 12 and 13. Cable sag effects can be checked comparing Bar-BC (which uses truss elements to model cables) with Caten- $B C$ (which uses elastic catenary elements instead) while the differences between Linear and Bar-BC graphic bars point out $P-\Delta$ effects (and beam-column effects). Beam-column effects are highlighted by the Caten-BC, Caten-C and Caten- $B$ graphic bars, which take into account full beam-column effects, moment-axial force interactions only and no beam-column effects, respectively. However, it must be emphasised that nonlinear effects cannot be absolutely evaluated because they are, in fact, strongly coupled. Yet, some qualitative 

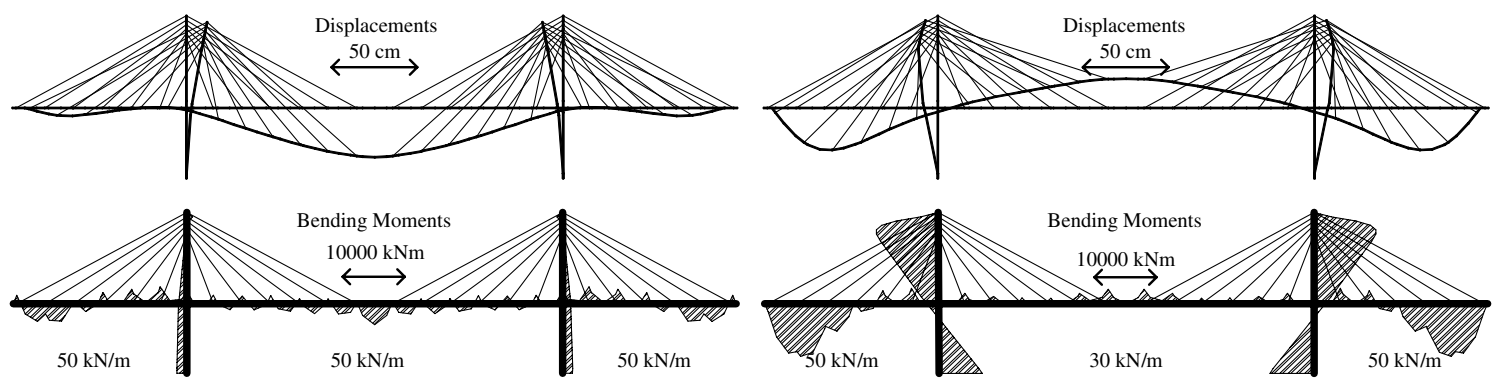

Load case [50 5050$] \mathrm{kN} / \mathrm{m}$

Load case[50 30 50] kN/m
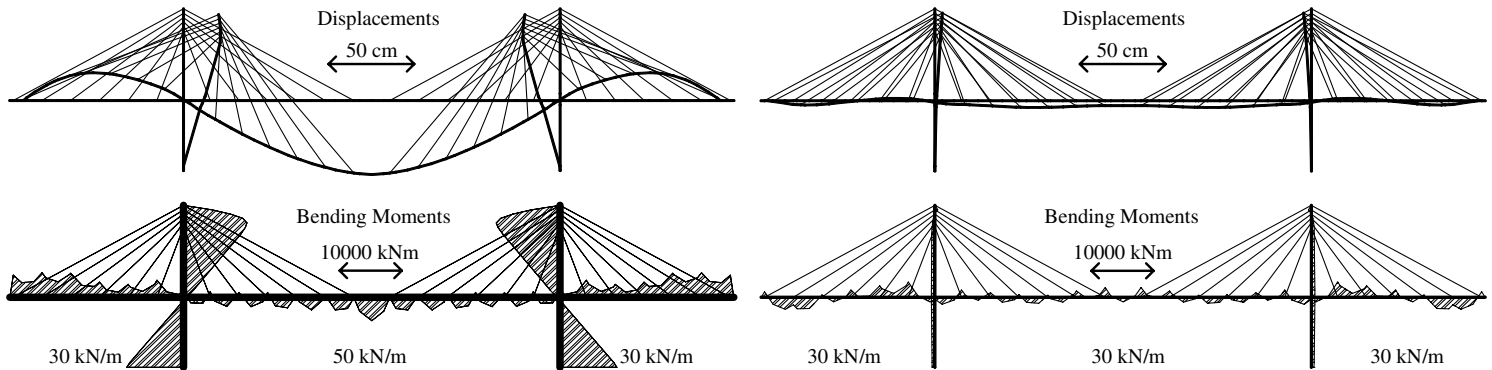

Load case[30 5030$] \mathrm{kN} / \mathrm{m}$

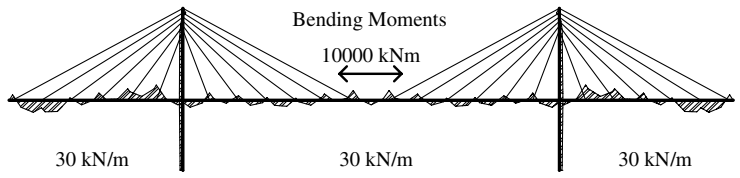

Load case[30 30 30] kN/m

Fig. 11. Cable-stayed bridge: deformed configurations and bending moments obtained through the "exact analysis" (Caten-BC).
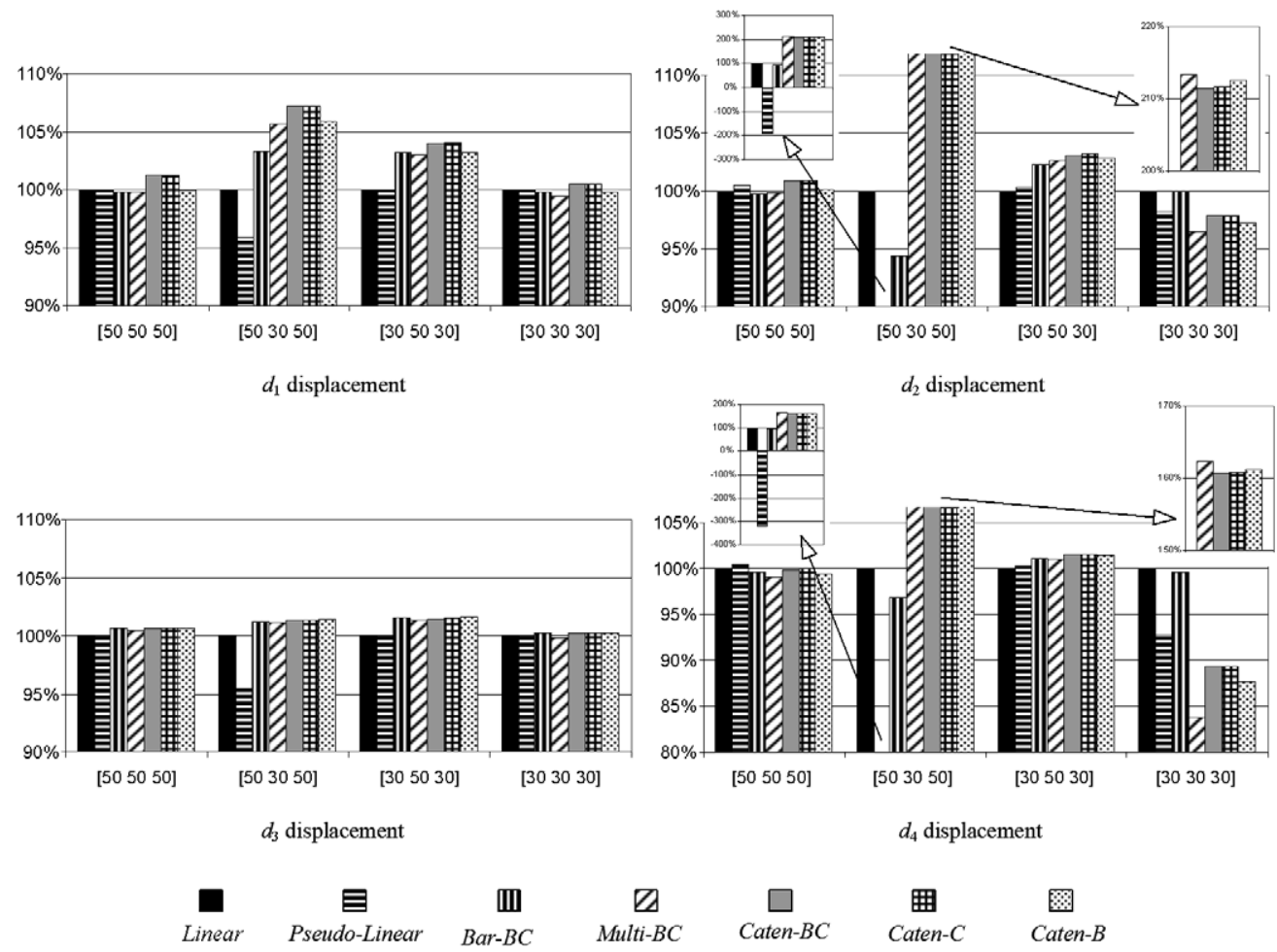

Fig. 12. Displacement comparisons between distinct analysis for each load case ( $d_{1-4}$ refers to Fig. 10). To check analysis label properties see Table 1.

conclusions can be drawn about the relative importance of each one.

As can be observed in the graphs of Fig. 12, the first load case [505050], which corresponds to uniform loads of $50 \mathrm{kN} / \mathrm{m}(\mathrm{dead}+$ live $)$ applied in the stiffening girders all over the deck, leads to almost no differences in the dis- placements $d_{1-4}$ between each analysis type. Therefore, the deformed configuration presented in Fig. 11 for this load case matches those obtained with every analysis types, i.e. Linear, Pseudo-Linear, Bar-BC, Multi-BC, Caten-C and Caten- $B$. The generalised stresses, such as the bending moments in the deck, the axial forces in the towers and 

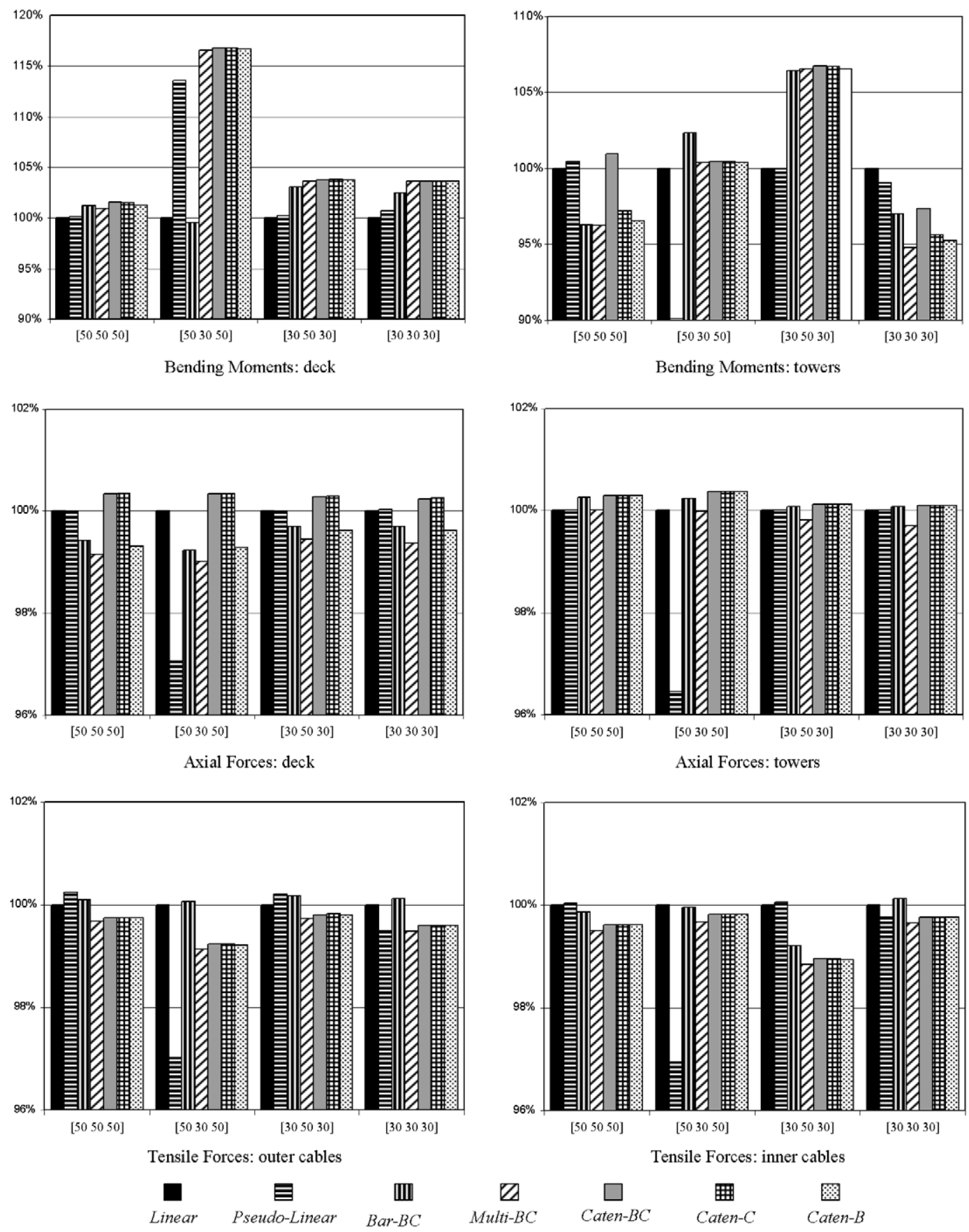

Fig. 13. Generalised stress comparisons between distinct analyses for each load case. To check analysis label properties see Table 1.

the cable tensions, due to this load case, show to be analysis-type independent. However, one can find slight differences in the bending moments of towers and in the axial forces of deck mainly due to large displacement effects (differences between Linear and Bar-BC) and beam-column effects (differences between Caten-BC, Caten- $C$ and Caten-B). As expected, no significant cable sag effects arise because of the high tensions on cables for this particular load case.

The cable sag effects come out in a prominent way for the second load case, i.e. [503050]. As one can observe in the corresponding graphs of Fig. 12, the differences between Bar-BC and Caten-BC are significant, especially for displacements $d_{2}(200 \%)$ and $d_{4}(160 \%)$, which means that truss elements are not good options to model cables with large deflections. The Pseudo-Linear analysis leads to unreliable solutions, as can be seen from the values of displacements $d_{2}$ and $d_{4}$, opposite in sign to the remaining solutions. Another important issue is that large displacement effects seem to be almost insignificant, because no major discrepancies arise between the Linear graphic bars and the $B a r-B C$ graphic bars. One should remark that no 
cable sag effect is supported by these analysis types and the beam-column effects are almost insignificant for this load case. Nevertheless, bending moment-axial force interaction can be identified in the axial forces of the deck, as can be concluded by comparing the graphic bars of Caten-BC and Caten-B. To highlight the differences in the deformed configuration, Fig. 14 is inserted in this paper, displaying the deformed configurations for the load case [503050] and different analysis kinds. Therein, the inefficiency of the Pseudo-Linear method to model the cable sag effect is put in evidence. Thus, both truss elements and modified elastic modulus elements shall be used carefully to model cables in cable-stayed bridges. In the former case, this is obviously due to the fact that the cable sag effect is not considered. As to the latter, the intense sag effect, coupled with a large displacement effect, leads to an unacceptable inaccuracy. As a matter of fact, it must be pointed out that no convergence was reached, in spite of the updating of the Ernst modulus in each iteration: an oscillating solution was, instead, verified. It seems that, for this load case, the cable sag effects are too important and cables cannot thus be modelled with the modified elastic modulus element. Large displacement effects seem to be much less important than the cable sag effects: the deformed configuration obtained from Linear (i.e. linear analysis) is close to that from nonlinear analysis using truss elements to model cables but supporting large displacements (i.e. Bar-BC). Replacing the truss element with the elastic catenary element (i.e. Caten-BC), the differences become larger, highlighting cable sag effects coupled with large displacements.

The differences shown by the graphic bars for the load case [305030] are mainly due to large displacement effects as can be observed in both Figs. 12 and 13. This is emphasized by the differences between Linear and Bar-BC for the bending moments on the deck and the towers and for the tensile forces in the cables of the central span. However, although less consequent than $P-\Delta$ effects, cable sag effects can be identified mostly in the differences of tensile forces of cables of the side spans, whereas beam-column effects can be identified in the graph for the axial forces of the deck.

Finally, the results obtained for the load case [303030] shall be analysed. As can be seen from Fig. 11, the deflected shape configuration due to this load case closely matches the design geometry, as required by the dead load condition, while the bending moments tend to a minimum and the girders behave much like a continuous beam on fixed supports. Looking over the displacements $d_{1-4}$, graphs from Fig. 12 show that no large differences arise from each analysis type. However, sag effects seem to affect the displacement values of $d_{4}$ : the one obtained from Caten-BC is less than $90 \%$ the value obtained from the Bar-BC analysis. A quick inspection over the generalized stress ratios, see Fig. 13, allows us to conclude that both sag effect and $P-\Delta$ effect increase the values of the bending moments of the deck and $P-\Delta$ effect decrease the bending moments of the towers. The differences obtained for the axial forces in both deck and cables are irrelevant and are mostly due to cable sag effect.

Some final remarks should be done. First of all we address our attention to the modelling of cables via multiple-straight links. Although being an effective way to model cable sag effect, some slight differences can be found between $M u l t i-B C$ and Caten-BC, especially in axial forces of the bridge deck, as can be observed in Fig. 13. However, no major differences in the tension values of both outer and inner cables are found. In this study six truss elements were used in Multi-BC to model the cables. The tension cables introduce axial forces in the structure which are functions of the angles $\alpha_{A}$ and $\alpha_{B}$. In order to allow a perfect match between the results using both catenary elements and the multiple-straight link method, one can use a higher number of straight links and/or a narrow mesh refinement near the cable ends. Secondly, one might expect some larger

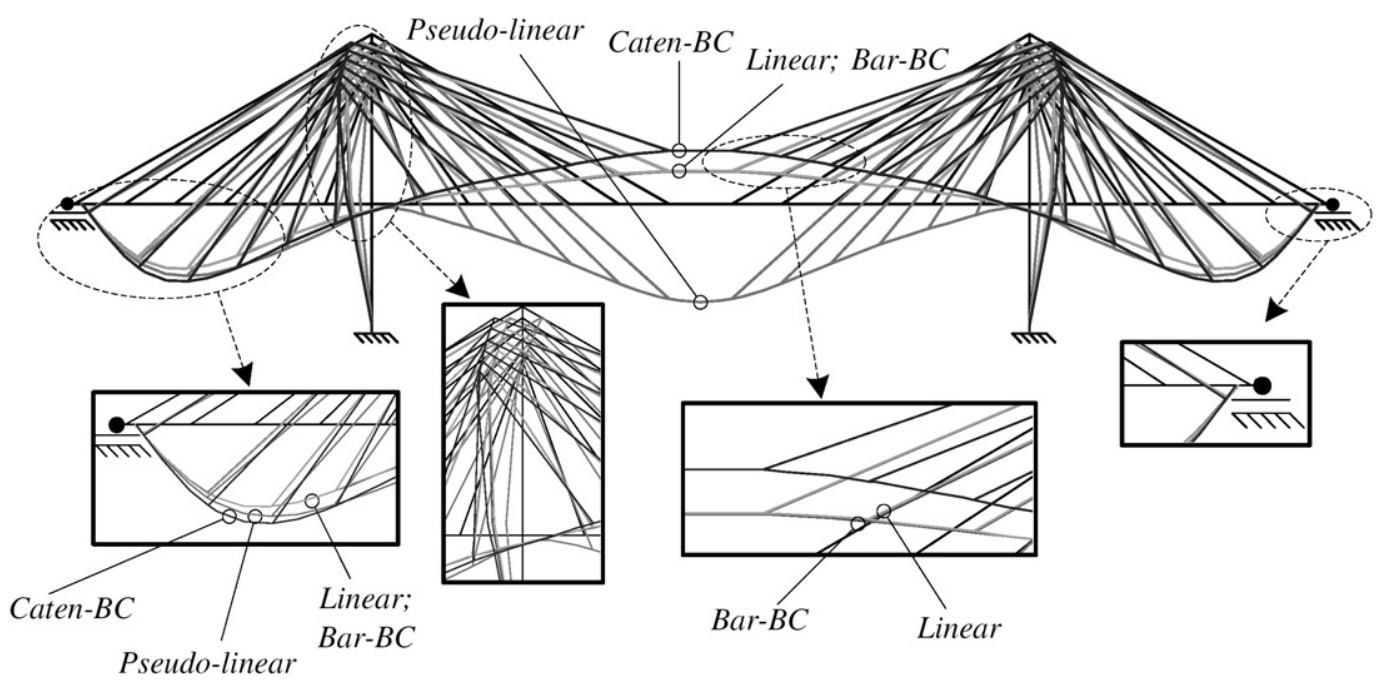

Fig. 14. Deformed configuration for the load case [503050] obtained by several analysis types. 
beam-column effects on the structure, due to the high compressions in both deck and tower beam elements compounded with large deflexion of the structure. This is not explicit in the graphs of Fig. 11 or 12. In fact, beam elements are small enough for beam-column effect to be turned into $P-\Delta$ effects and, in the other hand, no objective conclusions can be made because geometrical nonlinearities are strongly coupled. However, such effect can actually be determinant to global or, at least, local behaviour of cable-stayed bridges subjected to loads near critical values.

\section{Conclusions}

Geometrically nonlinear effects were evaluated for static analysis of a steel cable-stayed bridge. Several numerical finite element models were used by adopting various finite elements presented both in this paper and in references. Linear analysis, pseudo-linear analysis, which is based in the modified elastic modulus truss element, and nonlinear analysis of the bridge were used.

The results show that cable sag originate the most important nonlinear effects and can be a decisive issue in the global behaviour of those structures, specially when large displacements due to specific load cases lead to low tensioned cables: the results show that displacements obtained by nonlinear analysis using elastic catenary elements can be twice those obtained using truss elements to model cables. This situation is potentially of uppermost importance in the erecting stages. As the deflection of the deck increases, the share of cable sag effect in the overall nonlinear response decreases when compared to the large displacement effect, and thus truss elements can be used to model the cables. However, the large displacements can lead to localised low stressed cables, amplifying cable sag effects, showing a strong coupling between the various nonlinear sources.

Linear analysis of modern long-span cable-stayed bridges, which have a high flexibility, does not provide satisfactory results as their geometrically nonlinear behaviour is not modelled. As far as the modified elastic modulus method is concerned, it must be carefully used, because it proves to be very limited or even inappropriate to simulate cables behaviour in both the pseudo-linear and nonlinear approach. The main justification is based on the fact that pseudo-linear method does not manage the coupling between the cable sag effects and the large displacements.

Beam-column effect does not seem to significantly contribute to the geometrically nonlinear behaviour of cablestayed bridges. Even though potentially important close to the ultimate load, neither moment-axial interaction nor bowing are important effects when compared with either cable sag or large displacement effects.

\section{References}

[1] Wang PH, Yang CG. Parametric studies on cable-stayed bridges. Computers \& Structures 1995;60(2):243-60.

[2] Negrão JHO, Simões LMC. Optimization of cable-stayed bridges with three-dimensional modelling. Computers \& Structures 1997; 64(1-4):741-58.

[3] Simões LMC, Negrão JHJO. Optimization of cable-stayed bridges with box-girder decks. Advances in Engineering Software 2000;31: 417-23.

[4] Ahmadi-Kashani K, Bell AJ. The analysis of cable subject to uniformly distributed loads. Engineering and Structures 1988;10: 174-84.

[5] Cheung MS, Li W, Jaeger LG. Nonlinear analysis of cable-stayed bridge by finite strip method. Computers \& Structures 1988;29(4): 687-92.

[6] Chucheepsakul S, Srinil N, Petchpeart P. A variational approach for three-dimensional model of extensible marine cables with specified top tension. Applied Mathematical Modelling 2003;27:781-803.

[7] Ernst HJ. Der e-modul von seilen unter beruecksichtigung des durchhanges. Der Bauingenieur 1965;40(2):52-5.

[8] Gimsing NJ. Cable supported bridges, concept and design. John Wiley \& Sons; 1997.

[9] Karoumi R. Some modelling aspects in the nonlinear finite element analysis of cable supported bridges. Computers \& Structures 1999;71: 397-412.

[10] McDonald B, Peyrot A. Sag-tension calculations valid for any line geometry. Journal of Structural Engineering 1990;116(9):2374-87.

[11] Peyrot AH, Goulois AM. Analysis of cable structures. Computers \& Structures 1979;10:805-13.

[12] Fleming JF. Nonlinear static analysis of cable-stayed bridges structures. International Journal of Computers and Structures 1979;10(4): $621-4$.

[13] Ren WX. Ultimate behavior of long-span cable-stayed bridges. Journal of Bridge Engineering 1999;4(1):30-7.

[14] Seif SP, Dilger WH. Nonlinear analysis and strength of prestressed concrete cable-stayed bridges. In: International conference on cablestayed bridges. Bangkojk, 1987.

[15] Rheinboldt WC. Numerical analysis of continuation methods for nonlinear structural problems. Computers \& Structures 1981; 13(1-3):103-13.

[16] Seydel R. Nonlinear computation. Journal of the Franklin Institute 1997;334(5-6):1015-47.

[17] Cella P. Methodology for exact solution of catenary. Journal of Structural Engineering 1999;125(12):1451-3.

[18] Freire A, Análise pseudo-linear e não-linear de pontes atirantadas metálicas, MSc Thesis, Coimbra University, 2002 [in Portuguese].

[19] Chen WF, Lui EM. Stability design of steel frames. CRC Press; 1991.

[20] Kassimali A, Abbasnia R. Large deformation analysis of elastic space frames. Journal of Structural Engineering 1991;117(23):2069-87.

[21] Meek JL, Loganathan S. Geometric and material non-linear behaviour of beam-columns. Computers \& Structures 1990;34(1):87-100.

[22] Oran C. Tangent stiffness in space frames. Journal of the Structural Division 1973;99(ST6):987-1001.

[23] Crisfield MA. Non-linear finite element analysis of solids and structures. Advanced topics, vol. 2. John Wiley \& Sons; 1997.

[24] Crisfield MA. A consistent co-rotational formulation for non-linear, three-dimensional, beam-elements. Computer Methods in Applied Mechanics 1990;81:131-50.

[25] Crisfield MA, Galvanetto U, Jelenic G. Dynamics of 3D co-rotational beams. Computational Mechanics 1997;20:507-19.

[26] Renton JD. Stability of space frames by computer analysis. Journal of the Structural Division 1962;88(ST4):82-103. 